\title{
Grupo e instituição: relações de poder na dialética de um processo grupal de aprendizagem
}

\author{
Shirley Martins de Macêdo*
}

\begin{abstract}
Aprensentam-se teorizações sobre processo grupal de aprendizagem, enfocando o papel do facilitador enquanto mediador entre o grupo e o contexto social mais amplo. A partir de um processo vivido por um grupo de alunos, num curso de pós-graduação, numa instituição particular de ensino, procura-se compreender como as expectativas de papéis e as relações de poder estabelecidas entre o grupo e a instituição podem estar relacionadas com o processo de aprendizagem. Conclui-se, principalmente, que as relações de poder podem ter sido determinantes do processo dialético que ocorreu no grupo.
\end{abstract}

Palavras-chave: Grupo, processo grupal, aprendizagem, instituição, poder.

\begin{abstract}
The group and the institution: power's relationship on dialetic of a group learning process Introduce the theories about group learning process, focusing the role of the conductor as a mediator between the group and the social context. Attempt to understand how the expectance of the roles and the power's relationship established between the group and the institution could be related to the learning process from a lived process of a student's group from a particular college's postgrado course. One conclude, principally, that the power's relationship could have been determinant to dialetical process occurred on the group.

Key words: Group, Group Process, Learning, Institution, Power.
\end{abstract}

Compreender um processo grupal de aprendizagem requer não somente alguns embasamentos teóricos concernentes ao tema, mas também experienciar com o grupo tal processo. Daí que teorizar apenas não diz muito do que é um processo grupal. Vivê-lo, senti-lo, caminhar com ele, tentar entender suas contradições, é algo que supera o limiar da teoria. Portanto, este artigo é o resultado da compreensão da autora do mesmo enquanto integrante de um processo grupal de aprendizagem e apresenta-se dividido em partes que caminham do teórico para o prático, da vivência para o conhecimento e deste

\footnotetext{
* Mestranda em Psicologia Clínica pela Pontifícia Universidade Católica de Campinas, Apoio: CAPES.

Endereço para Correspondência: Rua Álvaro Antônio Zini, 418, Jd Chapadão, Campinas, SP - CEP 13.066-150, e-mail: shirley@zeus.puccamp.br
}

para uma compreensão da dialética das relações de poder deste processo.

\section{O que é um Grupo}

Um grupo de seres humanos pode ser definido de diversas formas. Para este trabalho, interessa compreender o grupo enquanto organismo que trabalha em torno de um objetivo. Mais particularmente, um grupo de pessoas que se reúnem para um processo de aprendizagem, que, em muitos aspectos, tem uma dinâmica que se assemelha a de um grupo terapêutico.

Davis (1973), estudando a questão da produção de grupo, define um grupo humano “como um conjunto de pessoas (por definição ou observação) entre as quais existe um conjunto observável ou definível de relações... Um grupo é um conjunto de sistemas mutuamente 
interdependentes de sistemas comportamentais que não apenas exercem influência mútua, mas também respondem a influências externas"'(p.4). Assim, um grupo de pessoas que se reúnem em torno de um objetivo, no âmbito total de suas relações de produção, estaria sujeito às influências internas mútuas entre os seus integrantes, quanto às influências do contexto onde o mesmo está inserido (por exemplo, sociedade ou instituição).

Foulkes \& Anthony (1977), ao estudarem o grupo analítico, salientaram que outros grupos humanos "espontâneos" (como associações desportivas, universitários etc) dispõem de consideráveis propriedades terapêuticas, no entanto, problemas interpessoais, muitas vezes, impedem que estas propriedades emerjam em benefício do crescimento do grupo. Para eles, o estudo da dinâmica terapêutica de um grupo surgido "espontaneamente" na sociedade, lança luz sobre a estrutura do mesmo, o que permite tratá-lo em benefício da realização de seus objetivos.

Numa concepção mais recente, que também evidencia os aspectos terapêuticos em torno dos quais um grupo caminha para atingir seus objetivos, Ribeiro (1994) é um dos autores que entende o grupo como um organismo vivo, que possui leis e movimentos próprios, característicos dos membros que o integram, mas que, no entanto, pertencem ao contexto sócio-cultural mais amplo. Dependendo de tais movimentos, muitas vezes inconscientes, o grupo estabelece sua própria cultura, ou seja, suas peculiaridades, passando a ser um todo que é maior que a soma dos elementos que o compõem.

Esta peculiaridade grupal é "desdobrada" pelo próprio grupo e se cria de acordo com as necessidades, contingências e possibilidades do mesmo. Isto constitui a unicidade, a singularidade do grupo enquanto organismo vivo.
Vivendo neste organismo, os participantes (incluindo o facilitador do grupo) descobrem, pela interação criativa, suas próprias capacidades, excitam suas consciências, potencializam as suas ações em prol da criação de si mesmos e de seus objetivos. Por isso, Fonseca (1988: p.175) considera o grupo como "configuração social intermediária que articula a realidade da esfera do indivíduo com as dinâmicas microssociais". Neste "jogo", o facilitador e os participantes ocupam status definidos, com as respectivas expectativas de papéis. Tais status e papéis são considerados por Fonseca (1983) enquanto instituições que se devem reciprocamente.

Além destas intermediações, o grupo tem uma função de mediação entre a participação do indivíduo e a totalidade social, onde alguns dos principais fatores são os aspectos históricos da sociedade mais ampla, que permeiam os movimentos do próprio grupo. Daí que o grupo é "uma produção do contexto sócio-histórico. Contexto que o 'constitui' e que o atravessa de ponta a ponta" (Fonseca, 1988: p.176).

Torna-se interessante, portanto, conceber o grupo enquanto um meio psicossocial inserido numa realidade social mais ampla e determinante (Boris, 1992), pois só assim o consideramos um mediador das relações entre o indivíduo e a sociedade.

A realidade sócio-histórico-cultural que permeia o grupo o influencia, no entanto, ao se reunir para viver uma situação grupal, os membros deste grupo "desvelam e criam uma 'realidade' coletivamente compartilhada $e$ uma consciência a ela relativa"(Fonseca, 1988: p.81). Isto pressupõe movimentos dialéticos, onde há transformação da consciência individual pelas ações grupais e vice-versa, permitindo que o grupo construa sua própria cultura. Ao construir sua própria cultura, um grupo tornase capaz de reconhecer, no seu processo, os ele- 
mentos não-saudáveis, chegando a filtrá-los e eliminá-los, a fím de se tornar um organismo mais saudável.

Compreendendo-se o grupo sob estes viéses, é possível realizar uma teorização psicossociológica sobre o mesmo. Boris (1992) realizou um estudo deste âmbito e, baseando-se em teóricos como Fonseca e Lane, acredita que num organismo grupal as contradições dialéticas são resultado, entre outros, da caracterização simultânea do grupo enquanto parte da sociedade de consumo e potencialidade de resistência à alienação e à manipulação às quais o mesmo está exposto dentro desta sociedade.

\section{O processo grupal de aprendizagem}

Vários autores têm estudado os processos que ocorrem dentro de um grupo e, mais particularmente, o processo grupal como um todo. Feder \& Ronall (s.d), por exemplo, caracterizam tal processo como um feixe de processos fenomenológicos que ocorrem ao nível intrapessoal, ao nível interpessoal e ao nível do próprio grupo enquanto sistema. O processo a nível do sistema "são os padrões dinâmicos de interação que se desenvolvem entre pessoas ao longo do que afeta o modo como as pessoas sentem-se sobre elas próprias e umas sobre as outras, assim como o modo como comportamse neste ambiente"'(p.12).

Boris (1992), por sua vez, salienta que é mais coerente falar em processo grupal que em grupo, pois um grupo só pode ser entendido enquanto processo histórico. Para este autor, todo grupo tem uma função histórica de manter ou transformar as relações decorrentes das relações de produção, reproduzindo, assim, a ideologia de uma sociedade.

$\mathrm{Na}$ opinião de Ribeiro (1994), o processo grupal é um elemento transitório que possui características visíveis e invisíveis. Como um pro- cesso, o grupo tem uma unidade permanente de mudança interna e externa. Sendo assim, os comportamentos visíveis, ou a postura grupal, podem indicar uma contaminação inconsciente, pela qual pode-se chegar à revelação da história interna do grupo, ou seja, aos conteúdos invisíveis. Acredita Ribeiro que "muitos dos processos de grupo ocorrem em nível inconsciente”( .36) e que “... tudo o que acontece no grupo é rico de significação, nada é neutro. Tudo é uma forma de linguagem" (p.37).

Fonseca (1983), mais centrado no processo de conscientização, defende que a criação de uma oportunidade para que os membros, em conjunto, realizem uma livre busca, permite a construção e tomada de consciência da realidade pelo grupo. Por isso é importante analisar um processo grupal enquanto uma dinâmica de interações: “... criar e recriar, criar-se e recriar-se"(Fonseca, 1988: p.114). Neste processo é que se dá a aprendizagem: do momento, do mundo, da realidade, de si e do outro, do grupo. Mais ainda: dá-se a aprendizagem dos processos que impedem o grupo de fluir livremente, de estabelecer seu lugar na sociedade.

Contudo, para haver aprendizagem é preciso que o grupo aceite mudanças, viva-as, intensifique-as. Na opinião de Ribeiro (1994), não existe aprendizagem sem mudança. Neste processo de aprendizagem, o grupo convive com dois medos básicos: o de perder o equilíbrio e o de enfrentar situações novas. Sua resistência, dessa maneira, é um processo de manutenção do status quo do próprio grupo, a fim de manter um equilíbrio frágil, sustentado à custa de mecanismos de auto-regulação. Quando o grupo consegue enfrentar estas barreiras, o processo grupal flui naturalmente. É um processo dialético, onde forças se encontram, se repelem, mas que, bem equilibradas, resultam na aprendizagem do grupo enquanto força afirma- 
tiva em desenvolvimento e no crescimento do mesmo enquanto organismo vivo.

\section{A facilitação para a aprendizagem}

Para que o grupo se envolva num processo de aprendizagem, torna-se importante a atuação do facilitador. É necessário, entre outros, que o facilitador tenha "tato" para sentir o processo característico de um grupo, "olhos" para enxergar os fenômenos grupais. Estas "táticas", se bem empregadas, permitem ao grupo "ser e fluir em um constante processo de conscientização"(Ribeiro, 1994: p.79).

O conhecimento do facilitador sobre fenomenologia, holismo e processo de aprendizagem grupal é importante. Ele precisa destes conhecimentos para conduzir o grupo dentro de uma visão humanística-existencial. Suas ações e postura são, entre outros, determinadas por estes conhecimentos. Tudo isto fornece ao facilitador um embasamento teórico fundamental, mas não esgota a sua ação. É preciso que ele tenha sensibilidade para respeitar as necessidades do grupo, a fim de que possa organizar sua percepção do fenômeno grupal que está ocorrendo. Neste sentido, o facilitador age como catalisador e intermediário do processo de reconhecimento da realidade por parte do grupo. Para isso, ele deve fluir com o grupo, não impondose à realidade, para não comprometer o livre curso das coisas: as coisas devem se auto-revelar naturalmente, e o facilitador conduz um grupo como um maestro conduz uma orquestra com cientificidade, tecnicidade, espontaneidade, sensibilidade, poder de entrega e capacidade para criar. A condução do grupo envolve teoria e técnica, intuição e criação coletiva.

Assumindo atitudes desta natureza, o facilitador de grupo prescinde à escolha dos membros e do próprio grupo, de acordo com a própria criação destes. Todos tendem a esco- lher, a descobrir e incorporar esta escolha - uma escolha individual e coletiva, pois o facilitador age nos níveis intrapessoal e interpessoal. Estes níveis se interpenetram, ou seja, interagindo com apenas um membro, o facilitador possibilita que esta interação tenha repercussão no coletivo grupal e vice-versa. Neste movimento, ele deve ter sensibilidade para não "misturar", para discriminar os dois níveis. A "mistura" pode ocorrer "eventualmente, quando o facilitador, em vez de dirigir-se especificamente a um individuo com quem quer comunicar-se, fala parao grupo como um todo"'(Fonseca, 1988: p.80).

Feder \& Ronall (s.d.) destacam bem o manejo do facilitador em agir nestes dois níveis, e acrescentam, como se viu no ponto anterior, o nível dos sistemas. Estes autores acreditam que o facilitador deve intervir nos três níveis, e suas intervenções devem ser no sentido de uma mensagem sobre a principal tarefa de aprendizagem do grupo, sobre quais interações estão surgindo e quais fenômenos estão ocorrendo no processo experiencial do grupo.

Possibilitando a constituição e elaboração dos conteúdos da consciência coletiva grupal, num processo "ótimo" de facilitação, o facilitador compartilha com o grupo do processo de descoberta e criação da realidade coletiva grupal, agindo como administrador de um processo de aprendizagem (Boris, 1992). Neste processo, a participação e criação individual de cada membro é bastante significativa, pois o verdadeiro facilitador não egocentriza o processo grupal em sua pessoa. O que ele deve possibilitar é a constituição deste processo a partir da participação e interação espontânea de cada participante, no sentido de criação e descoberta da realidade grupal, e do próprio processo individual de cada membro. Agindo assim, o facilitador torna-se um parceiro da criação dos membros e do grupo. É interessante salientar, contudo, que as funções do facilitador são se- 
cundárias diante dos desdobramentos espontâneos da criação individual e coletiva dos participantes do grupo.

Além de todas estas prerrogativas, é importante que o facilitador conheça efetivamete a realidade sócio-histórica em que ele, o grupo e os outros participantes deste estão inseridos. Desta forma, ele pode refletir sobre a situação sócio-histórica do sistema social mais amplo, a fim de compreender as tensões ao nível da atualidade existencial do grupo e as dinâmicas vivenciais e interacionais do contexto grupal.

Como admite Fonseca (1983: p.160), “o facilitador é um elo de articulação da configuração de poder do sistema social mais amplo com o grupo como sistema diferenciado". Assim, como intermediário entre a totalidade social e o grupo, ele deve conhecer o que configura o papel do grupo no sistema social e como o grupo está desenvolvendo a sua consciência coletiva neste sistema.

A partir de atitudes como estas, o facilitador implementa o seu papel sócio-pedagógico, no sentido de possibilitar a aprendizagem grupal, devendo explicitar as necessidades do contexto sócio-histórico em que o grupo está inserido e deixando transparecer a sua oposição às tendências aniquiladoras da sociedade (Boris, 1992). Ele é, portanto, “um agente social destacado e responsável pelo desempenho da instituição grupal perante a sociedade, sendo depositário parcial do poder institucional, definido por esta mesma sociedade, frente ao grupo e seus participantes"'(p.28).

\section{A dialética das relações de poder num grupo}

Boris (1992), buscando em Pichon-Rivière parte dos respaldos para expor suas idéias de como se analisar um processo grupal, coloca que a proposta dialética possibilita "capacitar ativamente o grupo para a resolução das dificuldades internas dos seus membros"(p.33), porque a dialética parte de situações cotidianas, permitindo uma análise sistemática das contradições emergentes, por onde se pode compreender as ideologias inconscientes. Mas ele acredita que uma simples análise dialética das relações centra-se apenas no grupo e defende que o grupo deve ser analisado dentro do sistema social em que está inserido, enfocando-se a relação dialética homem-sociedade, e atentando-se para os vários momentos históricos desta relação. Ele amplia, então, sua análise considerando o materialismo dialético e propondo alguns passos para isso.

Neste trabalho, não se pretende uma análise materialista-dialética. Não se pretende analisar, entre outros fatores que requerem uma análise deste âmbito, o grupo através de seus membros e do desempenho de seus papéis, mas enquanto um todo integrado. Assim, não se considera fielmente todos os passos propostos por Boris (1992), mas algumas de suas dicas para a compreensão de um processo grupal, através da dialética das relações de poder, como por exemplo:

1. partir da idéia de que o indivíduo é alienado, ou seja, é produto de um sistema social que opera ideologicamente (capitalismo); age e interage influenciado pelo status quo mantenedor dos papéis sociais; e reproduz este sistema social;

2. realizar uma análise do tipo de inserção grupal na instituição na qual o grupo está inserido.

3. no nível do desempenho de papéis deve se assentar a análise dialética de um processo grupal, porque neste nível se reproduz a luta pelo poder e a relação dominador-dominado, expressando-se os movimentos constituintes da dialética desta relação. 
Estes passos (e os outros propostos por Boris, não considerados aqui) permitem a compreensão das contradições que surgem num processo grupal, pois a profundidade da análise do desempenho de papéis propicia uma percepção mais clara da luta pelo poder, das relações de dominação, das oposições, negações, contradições e, principalmente, da negação da negação, que constitui a essência da dialética grupal e que possibilita a transformação.

É importante salientar que Boris (1992) propõe seus passos de análise como alternativas para o próprio facilitador que conduz um grupo. Contudo, o que se pretende aqui é analisar um processo grupal de aprendizagem após este ter ocorrido, recorrendo-se alguns passos de sua proposta, a fim de compreender como tal processo pôde ter sido influenciado pelas expectativas de papéis e pelas relações de poder estabelecidas entre o grupo e a instituição na qual o mesmo estava inserido.

\section{O grupo}

Pode-se considerá-lo um grupo espontâneo, pois os 19 membros que o formavam deliberadamente participaram de um processo seletivo que os levou a realizar um curso de pósgraduação.

Enquanto grupo, os membros eram bastante integrados e companheiros. Muito interessados na formação profissional, os membros pareciam dedicar-se bastante aos estudos. Mantinham, entre outras coisas, relações satisfatórias com todos os professores, mesmo que com a instituição constantes problemas referentes a pagamento de mensalidade ocorressem.

Geralmente, os professores discutiam o programa da disciplina com o grupo, o que possibilitava a este uma certa participação no rumo das aulas. No entanto, o grupo se apresentava mais aberto aos professores que permitiam a vivência da disciplina e não somente se vinculassem aos aspectos estritamente didáticos.

Problemas como trabalhar durante o dia e realizar o curso à noite, muitas vezes serviam como justificativa para a falta de alguns, assim como para o adiamento da entrega dos trabalhos acadêmicos. Estes problemas não pareciam dificultar o relacionamento destes membros com os professores e com a instituição, mas tinham repercussão na participação dos mesmos em sala-de-aula, participação esta que também era prejudicada pela sobrecarga de trabalhos "acumulados" de outras disciplinas anteriores à que estava sendo cursada.

\section{A instituição}

Uma universidade particular. Diante do grupo, era representada pelos professores e, mais particularmente, pela coordenação do curso, especificamente por um professor que também havia lecionado uma disciplina ao grupo.

O coordenador expôs, no início do curso, alguns critérios chave fixados pela instituição. O sistema de aulas consistia, basicamente, em cada disciplina ser dada em período intensivo de uma a duas semanas (dependendo da carga horária da disciplina). Quando uma disciplina tivesse período muito intensivo (incluindo o sábado) e tivesse carga horária acima de 45 horas, geralmente o grupo tinha um intervalo de uma semana entre uma disciplina e outra. $\mathrm{O}$ tempo de entrega para os trabalhos estava fixado para 45 dias após oúltimo dia de aula de cada disciplina.

As relações entre o coordenador e o grupo nunca apresentaram nenhum indício de abalo. Sempre preocupado com a qualidade do curso, o coordenador mostrava-se disponível em escutar as propostas do grupo e sempre procurava um acordo satisfatório para ambas as partes (grupo e instituição). Estes acordos, muitas vezes, diziam respeito a horário das aulas, 
datas de entrega dos trabalhos (ou adiamento dos mesmos), bolsas de estudo, pagamento das mensalidades, andamento de disciplinas, relacionamento grupo-professores etc.

\section{O facilitador}

Professor que, anteriormente à disciplina a que se refere o processo, já havia lecionado outra ao grupo. Na primeira disciplina, o seu relacionamento com o grupo foi por demais satisfatório, além do que ocorreu um ótimo processo de aprendizagem acadêmica e interpessoal, devido a isto, era tido como amigo.

Sua competência profissional já era do conhecimento de todos os membros do grupo muito antes destes entrarem em contato com ele (muitos até já o conheciam pessoalmente), visto que, na área de interesse do curso, ele era bastante conceituado.

Foi escolhido pela instituição para lecionar a segunda disciplina em substituição a um outro professor que também já havia lecionado ao grupo, mas que, como será mostrado mais adiante, por motivos institucionais não assumiu a tarefa.

\section{$O$ fato e suas conseqüências na aprendizagem}

Não se considerará para a compreensão do processo grupal os motivos institucionais que levaram o professor que haveria de lecionar a disciplina a deixar de fazê-lo. O que interessa, aqui, é o fato dos desacordos surgidos entre o grupo e a instituição, em decorrência da substituição da disciplina, no que tange à programação do curso, da referida disciplina, ao horário e à época a ser cursada.

A disciplina estava prevista para um mês de outubro. Tudo vinha transcorrendo dentro da programação prevista. No dia da primeira aula desta disciplina, contudo, o grupo foi avisado pelo coordenador (quase duas horas depois do horário previsto) que o professor não mais lecionaria. O grupo ficou em "polvorosa": "o que fazer agora?".

O coordenador tentou fazer um acordo. A princípio, como ficaria difícil a substituição imediata do professor, o grupo, junto com o coordenador, achou viável um encontro de final de semana (dois dias) em forma de workshop vivencial para substituir a disciplina. A viabilidade disto consistia em que: estes dois dias cobririam a carga horária da disciplina (30 horas); realizava-se algo que, há algum tempo, já vinha despertando o interesse do grupo (e até considerado satisfatório para os processos grupais que vinham ocorrendo); o grupo teria a oportunidade de vivenciar teoria a partir de sua própria experiência; além do que isto não atrasaria o andamento do curso, pois seria feito num final de semana próximo.

Entretanto, dois problemas se colocavam: era preciso, no mínimo, dois facilitadores para encaminhar este workshop, visto o tamanho do grupo; e deveria ser encontrado um lugar adequado para a vivência. As soluções que apareceram foram as seguintes: o coordenador se propôs a ser um dos facilitadores e convidaria um antigo professor do grupo neste curso; um dos alunos se comprometeu a encontrar um lugar em que o grupo e os facilitadores pudessem passar os dois dias.

Estas propostas, contudo, deveriam ser encaminhadas pelo coordenador à direção da instituição para fins de aprovação. Mesmo assim, ficou acordado que naquela semana não haveria mais aulas e o grupo, ao retornar na semana subseqüente para cursar a próxima disciplina, ficaria a par da posição da instituição em relação à proposta.

Ao reiniciarem as aulas, o coordenador disse ao grupo que a instituição não acatou a 
proposta, alegando que um workshop não seria condizente com o conteúdo do curso (o curso era teórico e não prático/vivencial) e com a ementa da disciplina. Sua contraproposta era a substituição do professor, mas a disciplina só poderia ser dada ao término de todas as outras, ou seja, ao término do ano letivo, pois, de acordo com a programação prevista, não haveria mais nenhuma semana intercalada entre as próximas disciplinas.

Isto queria dizer que o grupo teria aulas no mês de fevereiro do ano seguinte, pois no mês de janeiro nenhum professor lecionaria na instituição. Houve novamente um tumulto. Muitas pessoas se queixaram por ter que voltar (nas férias) para ter aula. Todos, empolgados com um workshop vivencial, disseram sentir-se frustrados pela falta de oportunidade de vivê-lo.

Considerando a situação do tempo não disponível até o final do ano letivo, o grupo acatou a contra-proposta. Um dos motivos para tal foi a informação dada pelo coordenador de que o professor substituto seria um ex-professor do grupo, pelo qual os membros nutriam respeito, admiração e amizade.

Chegando em fevereiro, iniciou-se a disciplina. No primeiro dia de aula, um sábado pela manhã, o grupo parecia satisfeito com a possibilidade de reencontro (tanto entre os membros, quanto com o professor/facilitador) $\mathrm{e}$ houve troca de cumprimentos afetuosos. A princípio, o professor queria saber como os alunos estavam no momento. Alguns se colocaram, expondo problemas pessoais e acadêmicos (entrega de trabalhos, decepção com notas). Um dos assuntos mais discutidos foi a futura separação entre os membros. Um deles (X) colocava a dificuldade que seria para ele esta separação. Outros (p.e, Y e Z) já vinham se "preparando" para tal separação, acreditando que seria uma "saudade gostosa", uma "lembrança boa". Outros acreditavam já ter mantido relações muito estreitas para se limitarem ao contexto acadêmico.

O professor expôs o programa e o conteúdo bibliográfico da disciplina. Propôs que queria filmar uma vivência com o grupo e, a partir disto, discutir a teoria contida nos textos e livros. O grupo gostou da idéia e chegou a um acordo com o professor (apesar deste ter demonstrado um olhar de receio - isto foi notado por um dos membros) de fazer esta filmagem no mesmo dia à tarde, na sala de uma clínica de psicologia onde um dos membros tinha um consultório. O motivo desta escolha foi que o grupo queria se sentir mais à vontade. Tudo incomodava, até as cadeiras da sala de aula não eram tidas como agradáveis para um encontro do tipo que estavam pretendendo fazer - um dos membros (K) disse: "eu queria sair daqui, nessas cadeiras eu me sinto apertada (estreitando os braços para perto do tórax). Quero me sentir mais à vontade. Isto aqui me lembra os trabalhos que eu tenho que fazer, essa agonia toda".

Todos saíram para almoçar juntos e, logo após o almoço, dirigiram-se para o local do encontro. Lá, acomodaram-se. O professor preparou a filmadora e iniciou-se o encontro. Neste momento, foi notável, devido à sua nova postura, como o professor tentou deixar seu papel docente em segundo plano e assumiu seu papel de facilitador.

Num primeiro momento, todos os membros em silêncio. Passados alguns minutos, alguns risos, olhares. Um dos membros propôs que cada um olhasse para dentro de si, sentisse e encontrar-se a si mesmo. Mais um momento de silêncio. Daí a pouco, iniciaram-se as colocações: Y expôs, a partir de uma experiência frustradora de ter visto uma pessoa com distúrbios de comportamento ser algemada em público, preocupação com o seu papel social enquanto psicólogo. Todos discutiram este tema. Depois W falou sobre as mudanças durante o ano ante- 
rior, e no presente, no sentido de não mais se preocupar tanto com a teoria e sentir mais a prática, as próprias vivências. W pareceu bastante mobilizado, chorando ao expor suas angústias. Novamente, X expôs seus sentimentos e sua dificuldade em relação ao fato de ter que se separar do grupo. Chateou-se quando ouviu dois colegas dizerem “Que drama, X!'. X explicou ter muita raiva da palavra drama, por coisas que ele já havia vivido antes, entendia a palavra num sentido "pejorativo". Um dos colegas se desculpou, alegando que não teve esta intenção, enquanto outro tentou fazer $\mathrm{X}$ entender que para ele a palavra drama tinha um outro sentido. K se interpôs ao diálogo e disse que estava irritado por muitos estarem achando X um "coitadinho". Z, no entanto, achava que ninguém estava vendo $\mathrm{X}$ como coitadinho porque $\mathrm{X}$ iria se separar do grupo, mas sim colocavam para ele os pontos positivos ocorridos durante o curso. Neste momento, um embate entre K e Z foi notado: $K$ acusava $Z$ de ser autoritário, enquanto $Z$ dizia que não era autoritário, apenas havia aprendido a fazer valer suas visões sobre as coisas, ocupando, assim, seu espaço e não deixando que ninguém prejudicasse os seus objetivos.

$\mathrm{Na}$ maior parte do tempo o facilitador permaneceu em silêncio, a ponto de, quando expôs, ao final do encontro, o que ele queria que o grupo fizesse com o material filmado (analisar de acordo com a teoria), Y perguntar o que ele havia feito, se passou quase o tempo todo calado, ou seja, Y não saberia como analisar a postura de um facilitador que praticamente permaneceu ausente. O facilitador lhe respondeu que depois, quando $\mathrm{Y}$ visse a filmagem e lesse os textos, iria saber melhor sobre as atitudes do facilitador.

$\mathrm{Na}$ segunda feira, todos assistiram a filmagem. A cada trecho do filme, havia uma pausa para debate. Poucos alunos leram o texto antes da aula e tentaram "enquadrar" o grupo na teoria. Nesta aula, como nas outras a partir da terça-feira, notou-se que alguns alunos chegavam bastante atrasados e saíam cedo. Com o decorrer do tempo, esta situação piorou. Mesmo que o professor exigisse a leitura prévia dos textos e tentasse retoma-los muitas vezes, os alunos não pareciam se interessar por isso. Não havia quase participação dos alunos em aula, a não ser sobre outros assuntos, externos ao conteúdo da disciplina. Estes assuntos interferiam no curso das aulas e o professor, apesar de toda sua capacidade docente, parecia não saber como dar um rumo melhor ao andamento da disciplina.

$\mathrm{Na}$ quarta-feira, os assuntos que prevaleceram foram o cansaço do grupo, as queixas sobre os trabalhos pendentes de outras disciplinas e o fato de estarem tendo aula nas férias. Muitos foram embora cedo. Novamente, Y alegou que tinha sentido falta, nas filmagens, da participação do facilitador. Agora ele tinha clareza que esta falta estava vinculada ao fato dele não ter sentido o facilitador enquanto membro do grupo. $\mathrm{O}$ facilitador disse que também tinha pensado sobre isso e chegou à conclusão, a partir desta intervenção de Y, que tinha uma preocupação diante da expectativa do grupo em relação à sua postura nesta disciplina, já que o grupo parecia acreditar muito no seu potencial.

$\mathrm{Na}$ quinta-feira, houve o que se poderia chamar de caos. O grupo não queria "nada" (K chegou a responder, quando o professor perguntou o que o grupo queria: "Eu não quero nada”). O grupo como um todo apresentava-se cansado, queixava-se sempre de algo. Y, porém, parecia querer buscar a raiz desse algo. Em silêncio, parecia observar e tentar compreender todos. Quando falou, queixou-se do professor não falar nada. Depois de uma conversa com o professor, Y chegou à conclusão de que estava cobrando algo, novamente, do professor, só não sabia o que era. Vez por outra, surgia uma con- 
versa sobre problemas institucionais: ou era a secretaria que atendia mal aos alunos, ou era um professor que havia sido injusto com as notas dos trabalhos. De repente, surgiu uma conversa sobre a substituição do professor e o fato que possa tê-lo levado a desistir de dar a disciplina: uns se colocavam a favor dele, outros da instituição. Novos momentos de silêncio e conversas paralelas. Pouco depois, T, chorando, começou a falar da sua decepção em relação à instituição para a qual havia trabalhado. Expôs que, neste dia, fazia exatamente um ano de sua aposentadoria e ele estava muito triste, porque muitos colegas seus estavam sendo demitidos. Ele havia ido à matriz do banco onde trabalhou $\mathrm{e}$ viu outras pessoas ocupando o lugar dos seus amigos, os quais $\mathrm{T}$ considerava competentes e injustiçados pelo banco. Enquanto $\mathrm{T}$ falava, alguns prestavam atenção e outros conversavam paralelamente. Uns foram embora antes de $\mathrm{T}$ terminar de falar. Começou o dispersar do grupo e ficaram apenas quatro pessoas: o facilitador, $\mathrm{Y}, \mathrm{W}$ e outro membro.

Y parecia muito pensativo e o facilitador perguntou o que ele queria dizer. Y falou que agora estava tudo muito claro para ele: o grupo estava se negando a aprender e que isso tinha uma relação direta com os desacordos institucionais ocorridos anteriormente entre o grupo e a universidade por causa dessa disciplina, pois o grupo se sentiu oprimido pela instituição. Achava Y que alguns membros discordaram entre si sobre a posição do professor substituído e que isso tinha provocado a dispersão do grupo, e que o grupo só aceitou a proposta da instituição porque gostava da pessoa (o facilitador) que iria substituir o professor. Y queria também, independentemente da vontade do grupo, pois não a conhecia, uma posição do facilitador frente ao problema pois, de qualquer modo, este representava a instituição. Depois da conversa, o facilitador, Y e os outros dois membros chegaram à conclusão de que o relacionamento do grupo com o facilitador e com a disciplina, em algum grau, tinha sido influenciado pelo problema institucional surgido há quatro meses atrás.

\section{Discutindo o processo}

Procurou-se analisar este processo grupal de aprendizagem levando em consideração o exposto no início deste artigo, através das idéias de Fonseca (1983), Boris (1992), Ribeiro (1994)e Feder \& Ronall (s.d.) que, respectivamente, propõem uma análise de processo grupal enquanto permeado pela dialética das relações de poder, representado pela dinâmica consciente-inconsciente, possibilitado pela dinâmica de interações sociais, e facilitado por alguém que atua nos níveis intrapessoal, interpessoal e do sistema.

No que tange aos aspectos de conscientização grupal, o membro Y parece ter realizado uma análise integradora do processo, quando apreendeu os fenômenos ocorridos ao longo dos encontros grupais. Portanto, realiza-se aqui uma complementação do "trabalho" de Y e, mais pormenorizadamente, uma compreensão dialética da dinâmica consciente e inconsciente que permeou este processo, buscando-se, primeiramente, compreender o grupo dentro da instituição, para depois esboçar os movimentos dialéticos ocorridos no grupo, a partir das relações de poder estabelecidas entre ele e a instituição.

$\mathrm{O}$ grupo foi formado a partir da espontaneidade dos membros. Durante o curso, ele já havia passado por fases de interação que o fazia agir enquanto entidade integrada e independente. Representava, então, indivíduos afetivamente integrados e potencialmente capazes de realizar as atividades propostas pela instituição, mas também indivíduos que faziam valer seus pontos de vista. Havia, devido a sua unicidade, uma potencialização de ações em prol dele mesmo. Por esta história interna (e externa), o grupo 
estabeleceu para si a sua cultura, uma cultura que, entre outros fatores, era determinada pelas necessidades, contingências e possibilidades grupais do momento. Assim, o grupo já tinha uma história na instituição, história que lhe permitia manter e transformar as relações tanto entre os membros quanto com a instituição. Como exemplo disso, tem-se o constante adiamento dos trabalhos. Parece que já havia no grupo a afirmação de uma força manipulativa que o fazia "mudar" determinadas situações em prol de seus interesses, necessidades e possibilidades. A tentativa de quebra dessa força, do status quo mantenedor de sua auto-regulação, representaria uma desorganização da cultura grupal. Passando a interferir no funcionamento grupal, a instituição promoveu um abalo dessa força.

Pode-se resumir que, durante o processo vivenciado na última disciplina, os comportamentos visíveis, como o silêncio e a falta às aulas, por exemplo, foram formas de linguagem que indicaram a contaminação inconsciente das relações de poder com a instituição e poderiam revelar a história interna do grupo. $\mathrm{O}$ grupo não aceitou mudanças, daí não ocorrer aprendizagem durante o processo, que lhe permitisse fluir livremente e estabelecer seu lugar na instituição. Assim, ele reagiu enquanto potencialidade de resistência à dominação da instituição.

$\mathrm{Na}$ sociedade mais ampla em que o grupo se inclui, desenvolve-se uma dinâmica que favorece a alienação, através da manipulação pelo poder dominante. O nosso sistema capitalista opera ideologias que representam a luta de poder e configuram uma relação dominador-dominado, uma realidade que é determinante das dinâmicas micro-sociais. Considerando as relações de poder, pode-se salientar, por exemplo, que direitos e deveres são aspectos constitutivos de sua dinâmica. Enquanto instâncias bilaterais, as obrigações implicam em direitos e vice-ver- sa. Nesta dinâmica, há uma relação do tipo: "se forneço algo, posso exigir algo".

Considerando-se a instituição educativa em questão, isto quer dizer, por exemplo, que enquanto a administração deve fornecer os suportes básicos a uma boa qualidade de ensino (obrigação da instituição/direito dos alunos), os alunos devem se esforçar para aprender, divulgando, assim, a qualidade de ensino para a esfera social mais ampla (obrigação dos alunos/direito da instituição).

O grupo e a instituição pareceram reproduzir estas relações de poder e operar ideologias que caracterizam a totalidade social mais ampla. Dinamizada na instituição, a interpretação de papéis por parte do grupo, coordenador e professor/facilitador pareceu permeada pela relação dominador-dominado, a partir do momento que ocorreu o abalo no seu relacionamento através do fato descrito. Ou seja, enquanto a instituição com sua contraproposta dominava o grupo, o grupo com sua negação de aprendizagem dominava a instituição. No primeiro caso, por representar a ideologia dominante na nossa sociedade, a instituição parecia estar mais acima na escala hierárquica. No segundo caso, afirmando-se também enquanto instituição livre e independente, o grupo fez valer seu poder por um processo inconsciente de manipulação, já que o poder manifesto poderia custar caro.

Um exemplo deste "medo" pode ser representado pela própria falta de contato entre os membros para que emergisse mais cedo o fenômeno de conscientização dos fatores que estavam levando o grupo a agir daquela forma. $\mathrm{O}$ medo de perder o equilíbrio, conseguido à custa de defesas para manter-se vivo, impossibilitou o grupo de enfrentar este desafio e encontrar consigo mesmo.

Estas ações grupais ocasionaram uma transformação das consciências individuais dos membros. Na maioria das vezes em que se pôde 
observar um discurso de problemas aparentemente individuais, os membros pareciam mascarar o real sentido de seus sentimentos e palavras, quando, na verdade, falavam pelo grupo. Ao ser negado o discurso em prol da coletividade grupal, o processo não se integrou.

O discurso do grupo no encontro do sábado pareceu representar bem a dinâmica inconsciente que permeava as relações de poder, a partir das expectativas de papéis. Por exemplo, a decisão de fazer o encontro do sábado fora da sala de aula poderia significar que, longe da instituição, o grupo teria lugar para exercer sua liberdade e afirmar o seu poder. Quando K fala das cadeiras da sala de aula, o seu movimento corporal parece significar a opressão da instituição. Mais adiante, enquanto $\mathrm{Y}$ expunha sua preocupação com o papel social do psicólogo e os outros membros davam andamento a esta discussão, W falava da angústia em relação à sua necessidade da vivência em prol da teoria, $\mathrm{Z}$ e K discutiam sobre autoritarismo e ocupação de "lugares" e X representava uma "coitadinha". Parece bem provável que esta dinâmica de discurso simbólico possa representar uma outra de um nível inconsciente: $\mathrm{X}$ questionava sobre o papel do grupo na instituição, W falava da angústia grupal por não ter realizado o workshop, $\mathrm{Z}$ defendia o lugar do grupo na instituição, que não foi respeitado por causa da "dominação" institucional e X pareceu configurar mesmo o papel de dominado que o grupo tinha assumido.

Neste encontro, porém, não havia uma organização lógica de discursos que permitisse estas afirmações. Já no encontro da quinta-feira, o discurso de $\mathrm{T}$ fornecia elementos simbólicos mais organizados. Ela falava, então, do banco, dos colegas demitidos e dos profissionais substitutos. Inconscientemente, isto poderia remeter à instituição, ao professor substituído e ao professor substituto.
Pensando-se no papel do professor/facilitador nesta dinâmica, pode-se concluir que o seu receio demonstrava o conflito dialético entre ser representante da instituição, ou seja, elo de ligação entre o grupo e a universidade, e facilitador do processo do grupo. Conhecendo a história do grupo e da sua posição diante do mesmo, o facilitador pareceu contaminado por estes fatores. Apesar de todo seu conhecimento teórico e de suas experiências práticas, participava da dinâmica inconsciente das relações de poder, o que lhe impossibilitou, no início, uma postura facilitadora ao desencadeamento do processo grupal, tanto de aprendizagem acadêmica quanto da conscientização dos conflitos que levavam aos movimentos dialéticos que o grupo estava vivendo. Contudo, ao transcender o seu próprio "medo", inseriu-se no sistema: ao conscientizar-se de seu papel, interveio ao nível interpessoal e facilitou, através da escuta a Y, a elaboração grupal ao nível do sistema, permitindo que o grupo chegasse ao fenômeno.

Assim, o grupo filtrou e eliminou os elementos não-saudáveis, transcendeu a uma forma saudável de conscientização e, conseqüentemente, possibilitou a aprendizagem grupal: uma afirmação da sua própria condição de organismo em crescimento, a negação da negação, onde as forças afirmativas se alastram, dando vazão à aprendizagem vital $\mathrm{e}$ ao crescimento individual e grupal.

\section{Conclusões}

A compreensão deste processo grupal de aprendizagem permite entender os aspectos terapêuticos ocorridos no grupo em questão. Já que se participou como membro do grupo, foi possível elaborar as etapas linearmente e compreender o processo a partir de uma vivência pessoal e não apenas de dados empíricos. Uma compreensão como esta, se ocorrida no próprio 
processo grupal, possibilitaria conhecer a estrutura do grupo e beneficiá-lo no sentido de realizar seus objetivos. Estudar a dinâmica terapêutica de qualquer grupo de aprendizagem, portanto, torna-se viável para engendrar políticas de ação que favoreçam o desempenho satisfatório do grupo.

Contudo, aprofundamentos teóricos sobre o tema assim como outras formas de análise (o materialismo-dialético, p.e.), poderiam fornecer uma compreensão mais acurada de todo o processo tratando, por exemplo, o grupo não como totalidade, mas como sistema constituído de partes que se interrelacionam e, investigando a dinâmica das relações de poder entre os membros, podería-se chegar a novos ângulos de compreensão sobre os fenômenos que impediram a aprendizagem acadêmica.

\section{Referências Bibliográficas}

Boris, G.D.J.B - O Processo de Cooperação na Psicoterapia de Grupo em Gestalt-Terapia. Dissertação de Mestrado. Fortaleza: UFCE, 1992.

Davis, J.H. - Produção do Grupo. São Paulo: Ed. USP, 1973.

Feder, R. \& Ronall, R. - Além da Cadeira Quente: Abordagens Gestálticas a Grupos. Introdução e Seção I. Maceió: texto sob revisão (s.d.)

Fonseca, A.H.L da - "Introdução"; "Instituição, Poder e Vida"; "Do Resgate da Incerteza e Recriação da Competência”. In Rogers, C.R. et all - Em Busca de Vida: da terapia centrada no cliente à abordagem centrada na pessoa. São Paulo:Summus,1983,p.135-189.

Grupo: Fugacidade, Ritmo e Forma - processo e facilitação na Psicologia Humanista. São Paulo: Ágora, 1988.

Foulkes, S.H. e Anthony, E.J. - Psicoterapia de Grupo: a abordagem psicanalítica. Rio de Janeiro, BUP, 1977
Ribeiro, J.P. - Gestalt-Terapia: o processo grupal. Uma abordagem fenomenológica da teoria do campo e holística. São Paulo: Summus, 1994. 